\title{
Education and Information Systems Routes and Activity Patterns agro-tourism Surat Thani
}

\author{
Nuchakorn.K, Tiranan.W, Jantira.P, Benjamin.C, Puriwat.L
}

\begin{abstract}
The purpose of research on the education and development of information systems, the route and form of agricultural tourism activities in Surat Thani are to study the patterns and activities of agro-tourism in Surat Thani, to study and gather information on agricultural tourism routes in Surat Thani, and to develop the information system in form and route of agricultural tourism in Surat Thani. From the interview using structured interviews, questionnaires, and shared observations, the samples used in this research were the main informants consisting of farmers engaged in agro-tourism activities, tourist attractions and other farmers who were involved in agro-tourism activities in each district. The results of the descriptive analysis were presented. From the basic information of agro-tourism in Surat Thani Province, there are currently 13 tourist sites including three eco-tourism destinations, three learning centers, two homestays and residences, four demonstration centers and one orchard: more followings are BangBaiMai Eco-tourism group, KhunTalay Eco-tourism group, Bang Po, ChangKob Shipyard Learning Center, Sufficiency Economy Learning Center, "Park Lung Song pure cold extraction coconut oil Learning Center". Baan Klong Noi Homestay, Monkey Farms Demonstration Training Center, a demonstration center for coconut and coconut shells, making a fishing rod for catching shrimp demo center, Coconut Sugar demonstration center, Artit Garden and Wangko Resort. Tourism forms and activities consist of 12 types, namely, cropping, animal husbandry, agricultural production, beautiful landscape, agricultural life park where tourists can walk in the garden themselves. Bang Bai Mai Floating market, rafting ropeway, rafting in the canal, demonstration of monkey training for agriculture and recreation travel directions. There are 3 main routes: Rural Highway No. 2007, Rural Road No. 4229 and Highway No. 420. Information System Route and Formation of Agricultural Tourism Activities in Surat Thani Province based on the survey area; researchers use the Google API to create a map route by identifying the coordinates of the tourist.
\end{abstract}

Key words: Information systems; routes; activities; agrotourism.

Revised Manuscript Received on June 22, 2019.

Nuchakorn.K, Department of Information Systems, Faculty of Management Technology, Rajamangala University of Technology Srivijaya, Nakhon Si Thammarat, Thailand 80110.

Tiranan.W, Department of Information Systems, Faculty of Management Technology, Rajamangala University of Technology Srivijaya, Nakhon Si Thammarat, Thailand 80110.

Jantira.P, Department of Information Systems, Faculty of Management Technology, Rajamangala University of Technology Srivijaya, Nakhon Si Thammarat, Thailand 80110 .

Benjamin.C, Department of Information Systems, Faculty of Management Technology, Rajamangala University of Technology Srivijaya, Nakhon Si Thammarat, Thailand 80110.

Puriwat.L, Department of Information Systems, Faculty of Management Technology, Rajamangala University of Technology Srivijaya, Nakhon Si Thammarat, Thailand 80110 .

\section{INTRODUCTION}

At present, the tourism industry is one of the income earners in Thailand. Visitors coming to the country are both Thai and foreigns. Thailand has encouraged people in the country to travel in the country even more. Thailand is a country where most of the population lives in agriculture. Tourism is promoted Ecotourism especially for agricultural tourism. To encourage tourists becoming aware of the livelihoods of local people and to increase income for farmers, agricultural tourism is a form of tourism that brings agricultural activities to tourism. Visitors are given the knowledge of agriculture and appreciate the outstanding scenery of the countryside.

Surat Thani is one of the major tourist destinations of the country because of the beautiful nature. There are islands such as Koh Samui, Koh Pha Ngan, Koh Tao and so on, the rainforest land rich in plants. It has all kinds of transportation, train, boat and airport. The majority of the people in Surat Thani are engaged in farmer such as farming, gardening. About $45 \%$ of the total land area is used for farming; major economic crops include rubber, palm oil, coconut oil, rambutan, durian and coffee. The fisheries will also be fisheries both salt water and brackish water. Moreover, there are also Coastal aquaculture and freshwater fishing.

Researchers have the idea to gather information on agricultural tourism by collecting the data of routes, forms and activities of agricultural tourism in Surat Thani, then setting up a website to collect information, routes, forms and activities of agricultural tourism in Surat Thani.

\section{LITERATURE REVIEW}

NatchaPiyavudsagul 2556, the study by survey area found that villagers in the studied area are interested to do that, make a homestay due to the fact that tourists are visiting throughout the season the whole year, and tourists are also keen to stay in the homestead agricultural tourism, therefore; the villagers are interested in upgrading their home into a homestay. However, to adjust the home as a homestay for visitors which are likely to increase in the future, it is necessary to educate them about homestay and home style needs to be ready and meet the standards of Homestay Thailand. Therefore, it is interesting to study this agricultural tourism, on the objective of evaluation of the potential of housing for homestay development in the area of agricultural tourism.

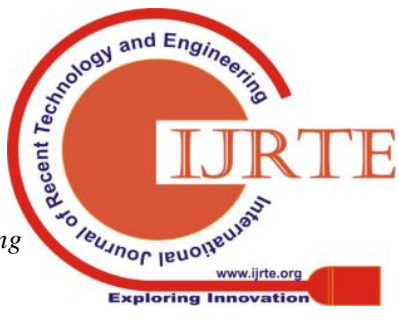


By applying homestay data at the national level in conjunction with geographic factors, this is an evaluation form of this study area and is analyzed by the weighted linear equation (WLC) to measure the potency of each house, and then the results are classified according to the potential level, which consists of very high potential, medium potential, and low potential, respectively. The study found that in 168 houses, there are $22.02 \%$ of homes with the high potential to develop as homestay, with a moderate potential of $58.33 \%$ (98 households) and with the low potential to develop as homestay $19.64 \%$ (33 households). Most homeowners are still in the middle. Each of the factors in the home's development is very important. If this research is to be completed, this project will help villagers to gain insights into how to increase their potential and how to develop their housing to be standard homestay on the area of agricultural tourism in the future. [5]

WaruneeKetsa-ad 2552, This study aims to evaluate the potential of agricultural tour of agricultural area in ThawiWatthana, Bangkok and to find ways to increase the potential of agricultural areas as appropriate for the agricultural. The results of the study were obtained from the evaluation of agro-tourism potential of ThawiWatthana area, Bangkok, by applying the evaluation form to evaluate the agricultural sources, using in-depth interview method and observation of 8 agricultural sources to find a way to develop tourism, then translated. It has been found that there was $63 \%$ of the high total potential for agricultural production; the overall low-potency assessment was only $37 \%$. For the 8 -items evaluation, there was high potential for linkage, close proximity to the main tourist attractions in the area of agricultural safety and basic facilities, respectively and low potential to improve on the signs to visit the agrotourism and tourism information services tourism management. That concluded the agricultural tourism potential of ThawiWatthana area is high. For information from the sub-group meeting on agro-tourism development, it was suggested that tourism promotion should be promoted in terms of knowledge and budget to establish a coordinating center and public relations, to tourists provide parking space, toilets, signage, and encourage tourism activities to accommodate more tourists and farmers have more income from selling agricultural products. The community is ready and the demand for agricultural tourism, the agricultural resources are attractive to tourists; this concluded that agricultural tourism of agricultural areas in ThawiWatthana Bangkok Metropolis has high potential. Therefore, it should promote agricultural tourism in ThawiWatthana area in various aspects including education and budget for community tourism activities. [6]

Sopon (2547) studied the "activities and agricultural tourism routes of salted hatchery producers in Samet, Chaiya District, Surat Thani Province". Chaiya Egg Production Group has developed into an agricultural tourism destination, a knowledgeable tour guide. The agricultural tourism, there is a visitor center offering a demonstration of the salty egg production. There are activities staying overnight and participating in lifestyle activities with the community. [7]

Teppakorn Na Songkhla (2011), this research involved the study of various forms and characteristics of agro-tourism activity in current agricultural resource management and interaction analysis between agro-tourism and agricultural resource management at agro-tourism sites in Changklang district. Seven farms, two private enterprises, and two farmer groups were involved in the study. The results from questionnaires and key informant interview methods showed that the agricultural activities in Changklang district used as agro-tourism activities were bee farming, mushroom cultivation, and organic farming in the form of agricultural demonstration/instruction, agricultural product distribution, or agribusiness guidance. These forms of agro-tourism activity have impacted on local agriculture in terms of the conservation of agricultural resources and the expansion of bee farming, mushroom cultivation and organic farming, as well as the value-added exploitation of local agricultural resources by tourism. The results of this activity have become outstanding characteristics of agriculture in Changklang district that have supported the expansion of agro-tourism. [8]

\section{METHODOLOGY}

\section{Research Design}

The study area of this research was based on the survey of agro-tourism sites, on the database of relevant agencies. Once you know the basics, ask the relevant agencies and visit the place to provide study areas that meet the objectives of the research.

From the processes above, selected agricultural tourism case study is divided into 7 sections as follows:

1. BangBaiMaiAgro-tourism Surat Thani

2. KhunTalay Tourist Group Agro-tourism Surat Thani

3. ChangKob Shipyard Learning Center Agro-tourism Surat Thani

4. Enriched Learning Center Agro-tourism Surat Thani

5. Learning Center for Making Cold Pressed Virgin Coconut Oil "Lung Song Garden", Surat Thani

6. Baan Klong Noi Homestay Agro-tourism Surat Thani

7. Ecotourism Bang Bo Agro-tourism Surat Thani

\section{Population and Sample Research}

The samples in this study were primary informants. In selecting the primary informant, visiting the site and using the information from the survey, the main informants are farmers who conduct agricultural activities, tourist Attractions, and the agency in the province of Surat Thani. In addition, other farmers are also involved in agro-tourism activities and farmers.

Each surfing Qualitative study by distributing the following informants:

1. Group Leader / Owner of agricultural attractions a total of 7 tourists were chosen as tourist destinations, as shown in Table I

2. Related agencies include:

2.1 Officer of Surat Thani Provincial Office of Agriculture and Cooperatives, responsible for promoting agricultural tourism.

2.2 Local administrative organizations are the two subdistrict, BangBaiMai and Khuntalay 
3. Community leaders in politics, local government: In each study, there were interviews with the headman of each district, BangBaiMai, Khuntalay and Klongnoi

4. Farmers in each district are not directly involved in the agro-tourism business, to find out how this group has been influenced by tourism, 14 selected by simple random sampling. There are three groups of tourists from 2-3 tourist destinations, based on the size of the group.

5. The people who contribute to the agricultural activities

Tables. 1 Research Sample

\begin{tabular}{ll}
\hline \multicolumn{1}{c}{ Landmarks } & \multicolumn{1}{c}{ Group Leader / Owner } \\
\hline 1. BangBaiMaiAgro-tourism Surat Thani & Senior Director, JariyaSriruk \\
2. KhunTalay Tourist Group Agro-tourism Surat Thani & SuwichakSanguanpan \\
3. ChangKob Shipyard Learning Center Agro-tourism Surat Thani & WuttipakornNantakasetra \\
4. Enriched Learning Center Agro-tourism Surat Thani & NattayaKaewtrainguan \\
5. Learning Center for Making Cold Pressed Virgin Coconut Oil & SomprasongSrithep \\
"Lung Song Garden", Surat Thani & \\
6. Baan Klong Noi Homestay Agro-tourism Surat Thani & PichetNetrachareon \\
7. Ecotourism Bang Bo Agro-tourism Surat Thani & NattapreeyaMuangrareun \\
\hline
\end{tabular}

\section{Research Tool}

A study of this research, data providers and tools are included as follows:

1. Structured interview

2. Questionnaire

3. Common observations

From the above, the data collection tools were designed for the various types of informants. The questionnaire was used to study the basic information of 7 agro-tourism sites. An in-depth qualitative study of agricultural tourism activities was conducted; interviews with all tourist leaders and related agencies are the office of agriculture and cooperatives, Surat Thani. Local administration community leaders are village headmen and the samples are farmers involved and not related to the tourism business.

\section{Data Collection Methods}

1. Structured interviews an in-depth qualitative study of agricultural tourism activities was conducted. Interviews with all tourist leaders and related agencies are the Office of Agriculture and Cooperatives, Surat Thani. Local administration Community leaders are village headmen, and the samples are farmers involved and not related to the tourism business.

2 . The questionnaire was used to study the basic information of 7 agro-tourism sites. The researcher worked with the Office of Agriculture and Cooperatives. Surat Thani The main coordinating center, the coordinator leads the tour leader at the tourist site for cooperation in the questionnaire. 3. Common Observation Data collection was done by two participant observation methods.

-First, the researcher appointed the farmer leader to lead the researcher visiting tourist site and meet with group leaders and observe the pattern, tourism activities include address survey, travel route

- Second, the researcher and the team visited the tourist attraction as a visitor, as a tourist to include information on tourism activities, include address survey, travel route.

\section{Methods and Data Analysis Tools}

Content crawler crawl verification, researchers are concerned about the content of the data collection tool to obtain information that can answer the research objectives.
In terms of quantitative data, the percentage value is used to describe the phenomena studied to classify Sequence and linkage each research objective how to analyze the data.

1. Form and activity of agro-tourism, analyze data by identifying key events or change, describe the development or change of various aspects, especially agricultural tourism the use of tourism resources, the concept of agro-tourism activities in identification and classification of agro-tourism activities.

2. The route of agricultural tourism at various points, researchers present using maps in Google map.

The authors of the accepted manuscripts will be given a copyright form and the form should accompany your final submission.

\section{RESULTS AND DISCUSSION}

The study and development of the information system for agricultural tourism in Surat Thani province, the research was conducted in March, 2560, the researcher conducted the data analysis, the results of the analysis are as follows:

1. Basic information on agricultural tourism in Surat Thani, there are 3 ecotourism sites, 3 learning centers, 2 homestays and residences, 4 demonstration centers and one orchard following: BangBaiMai. Eco-tourism group, KhunTalay Eco-tourism group, Bang Po ,Changkob Shipyard Learning Center Learning Center Learn to make cool coconut oil, cold extract "Park Lung Song" Baan Klong Noi homestay, Monkey Farms Demonstration Training Center, a demonstration center for coconut and coconut shells, Fishing rod for Shrimp Demo, Coconut Sugar Demonstration Center SuanSawan Sun Resort

2. Form and activity of agro-tourism in Surat Thani consists of 12 forms of cropping, animal husbandry, agricultural production, beautiful landscape, agricultural life Park where tourists can walk in the garden themselves. Moreover, Floating Market, rafting ropeway, rafting in the canal, and monkey training demonstration are more places for the recreation.

3. Surat Thani Agricultural Tourism Route, the main routes are divided into 3 routes: Rural Highway No. 2007, Rural Road No. 4229 and Highway 420. 
4. Information system of route and form of agricultural tourism activities in Surat Thani province, the researcher developed the information system and route of agricultural tourism activities in Surat Thani through Google API by identifying the coordinates of agricultural tourism in Surat Thani. The information and route system of agricultural tourism activities in Surat Thani Province via URL: https://goo.gl/1ZNAnjas shown in Fig. 1. To 4.

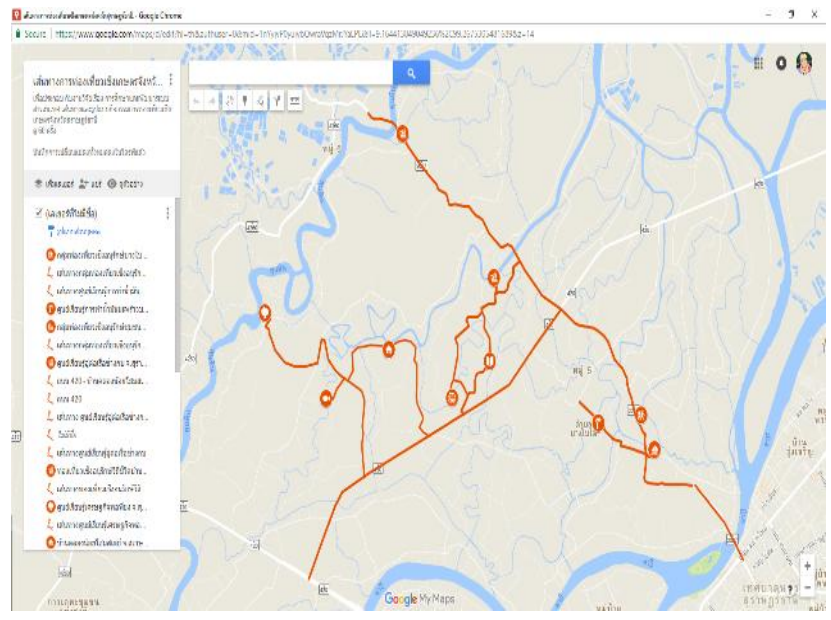

Fig. 1 Rural Highway No. 2007.

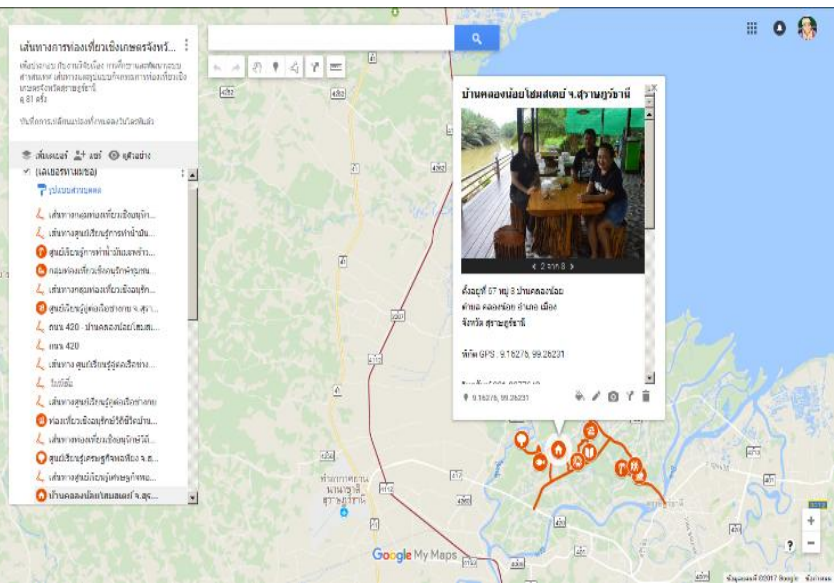

Fig. 2 Ban Klong Noi Homestay at the assigned coordinates
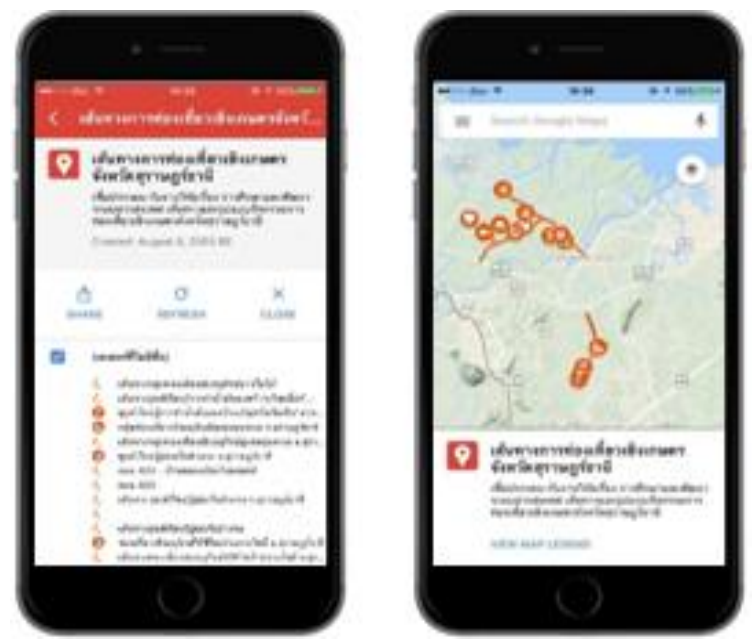

Fig. 3 Usage via mobile applications
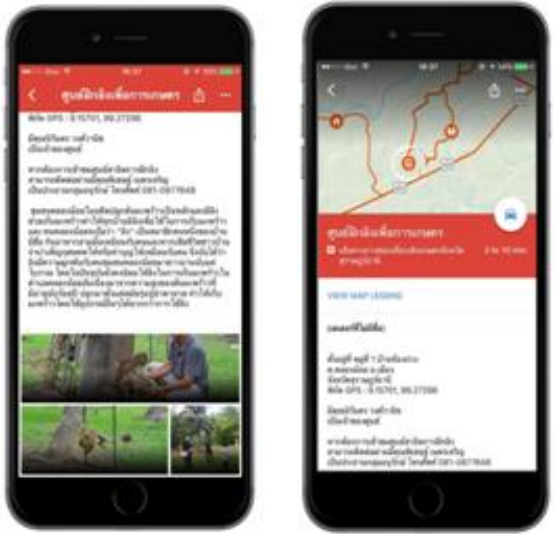

Fig. 4 click to view tourist attractions through mobile phones.

\section{ACKNOWLEDGMENT}

A study of research project on education and development of information system, the route and form of agricultural tourism activities in Surat Thani, this was accomplished with the support of the budget of the year 2016 from Rajamangala University of Technology Srivijaya. Nakhon Si Thammarat Campus. The research was highly appreciated and received great support from local people. Surat Thani until the research was completed. The students are very grateful for this opportunity.

Thank you all faculty and staff, the support is very good over the past period. Thank you for your support and encouragement in all aspects of your parents, family members, students, counselors, provide advice on all aspects that lead to the completion of this study.

Finally, the results of this study hopefully will be very useful to the general interest. If there are any defects, the students are welcome to visit and apologize here.

\section{REFERENCES}

1. What is API? April 1, 2015, from http://meewebfree.com/

2. What is Google Maps for Business? Founded on April 1, 2015, from http://www.tangerine.com/what-is-google-maps-for-business/

3. KritsadaChanrob (2016). What is PHP Founded on April 1, 2015, from https://www.gotoknow.org/posts/428663

4. (Geographic Information System: GIS). Founded on April 1, 2015 from http://www.gisthai.org/about-gis/gis.html

5. NatchaPiyawutSakul. Potential Assessment of Housing for Homestay Development. In the area of agro-tourism, the area of agro-tourist attraction, Moo 3, Klong Dam. Khlong Khuean District Chachoengsao. Chulalongkorn University Secretariat, 2013

6. WaruneeKetatad. Evaluation of agricultural tourism potential of ThawiWatthana area. Bangkok. Mahidol University Salaya, 2009

7. SophonBoonlum, JutamasKorangsri and BenjamasPimja. Events and routes Agricultural Tour of Salted Eggs Group, Samet, Chaiya District, Surat Thani Surat Thani Rajabhat University, 2004

8. Teppakorn $\mathrm{Na}$ Songkhla,BunchaSomboonsuke Interaction between agro-tourism and local agricultural resource management: A case study of Changklangagro-tourism, Nakhon Si Thammarat province.Prince of Songkla University,(2011).

\& Sciences Publication 